\title{
Correction to: Potential future climate-induced shifts in marine fish larvae and harvested fish communities in the subtropical southwestern Atlantic Ocean
}

\author{
Micheli D. P. Costa ${ }^{1} \cdot$ Kerrie A. Wilson ${ }^{2} \cdot$ Philip J. Dyer $^{3} \cdot$ Roland Pitcher $^{4}$ • \\ José H. Muelbert ${ }^{5,6}$ - Anthony J. Richardson ${ }^{3,4}$
}

Published online: 6 July 2021

(C) Springer Nature B.V. 2021

The online version of the original article can be found at https://doi.org/10.1007/s10584-021-03097-x

\author{
Micheli D. P. Costa \\ micheli.costa@deakin.edu.au \\ Kerrie A. Wilson \\ kerrie.wilson@qut.edu.au \\ Philip J. Dyer \\ uqpdyer@uq.edu.au \\ Roland Pitcher \\ roland.pitcher@csiro.au \\ José H. Muelbert \\ docjhm@furg.br \\ Anthony J. Richardson \\ anthony.richardson@csiro.au
}

1 School of Life and Environmental Sciences, Centre for Integrative Ecology, Deakin University, Victoria 3216, Australia

2 Queensland University of Technology, Brisbane, Queensland 4000, Australia

3 School of Mathematics and Physics, The University of Queensland, St. Lucia, Queensland 4072, Australia

4 Commonwealth Scientific and Industrial Research Organisation (CSIRO) Oceans and Atmosphere, Queensland Biosciences Precinct, St Lucia, Brisbane, Queensland 4067, Australia

5 Laboratório de Ecologia do Ictioplâncton, Instituto de Oceanografia, Universidade Federal do Rio Grande, Campus Carreiros, Avenida Itália Km 8, Rio Grande, Rio Grande do Sul 96203900, Brazil

6 Institute for Marine and Antarctic Sciences (IMAS), University of Tasmania (UTAS), Private Bag 129, Hobart, Tasmania 7001, Australia 


\section{Correction to: Climatic Change https://doi.org/10.1007/s10584-021-03097-x}

The affiliation of author Kerrie A. Wilson was incorrect in the original publication and this has been corrected.

Correct affiliation is Queensland University of Technology, Brisbane, Queensland 4000, Australia.

Publisher's note Springer Nature remains neutral with regard to jurisdictional claims in published maps and institutional affiliations. 